\title{
The Influence of Self-Editing on Micro Skills Development in Academic Writing in English as a Second Language
}

\author{
Tatiana Pospelova \\ National Research University Higher School of Economics
}

\begin{abstract}
Correspondence concerning this article should be addressed to Tatiana Pospelova English Language Department for Economic and Mathematical Disciplines, National Research University Higher School of Economics, 26 Shabolovka St., Moscow, Russian Federation, 119049. E-mail: tpospelova@hse.ru
\end{abstract}

\begin{abstract}
Self-editing skills are extremely important in foreign language learning; without them university students tend not to write appropriately in academic contexts. These skills are, however, often less developed in school graduates and it is thus essential to understand the challenges faced by university students. The present study was conducted to answer the research question: whether self-editing as a final component of written production can boost the writing micro skills of learners. It analyzes English-language essays written by 50 second-year ESL students in the Faculty of Economics at the National Research University Higher School of Economics, Moscow, and reports on the most frequent errors committed in their formal writing. The aim of this study is to focus on the stage of self-editing and identify the role of self-editing in micro skills development. Findings reveal that students are most often weak at producing coherent and cohesive paragraphs; they also lack appropriate argumentation and are often inaccurate in using grammatical structures and lexis. Results also suggest, however, that $\mathrm{L} 2$ writing students can improve their own writing by transferring micro skills they learn when editing texts. The present study may contribute to teachers' views on developing micro skills of student writers.
\end{abstract}

Keywords: self-editing, writing micro skills, typical errors, essays

Academic writing has started to be seen as a desired aspect of students' academic and professional training across the disciplines in the majority of universities. Student programs are increasingly using academic writing in English as a second language as a graded component of students' coursework. The expectation is that, at this educational level, graduate students need to master a variety of written genres. Writing tasks vary from writing short answers in exams, doing some written assignments like reports, seminar research papers or term papers, to writing dissertations and theses in ESL. A number of universities employ all of these sets of genres as they are considered integral to not only their graduate students' educational training but also their professionalization and professional identity development. However, upon entering universities, students do not necessarily already have skills in the written language and, consequently, they often face difficulties of various kinds. Despite the fact that secondary education also implies teaching writing skills, schools often focus more on boosting grammatical and spelling rules than on the content of writing. Although this deficit mainly concerns the native language of students, it also has an impact on their acquisition of writing skills in a second language, particularly in English. "Writing production is multifaceted and includes a number of skills that must work together", particularly organizing essays coherently with appropriate sentence structure and vocabulary, "spelling, handwriting, prior knowledge of the topic, and familiarity with models of academic literacies or genres", where high quality writing depends on this large constellation of skills and abilities (TEAL Center, 2010, p. 1). T. Baranovskaya et al. (2011, pp. 52-56), A. Gillet (1996) and other researchers see writing as the most problematic use of English in tertiary education. It is a complex and rather difficult to acquire process which requires from learners a number of academic skills (micro and macro) and comprises several stages, namely, prewriting, 
drafting, and revising. According to the Common European Reference Framework for languages (CEFR), an advanced learner can write clear, well-structured expositions on complex subjects, underlining the relevant salient issues, expand and support points of view at some length with subsidiary points, reasons and relevant examples (Council of Europe, 2011). It is worth pointing out that the invariant kernel of writing skills correspond to "can do" statements used in the CEFR to describe what learners can do at various levels of skill in speaking, writing, listening and reading. H.D. Brown, who was the first to categorize skills into micro and macro categories, defines micro skills of written production in the following way. Having acquired each of these micro skills, students are supposed to produce graphemes and orthographic patterns of English; produce writing at an efficient rate to suit the purpose; produce an acceptable core of words and use appropriate word order patterns; use acceptable grammatical systems (e.g., tense, pluralization), patterns, and rules; express a particular meaning in different grammatical forms; use cohesive devices in written discourse (Brown, 2004, p. 221).

All the steps in the writing process - planning, organizing, presenting, re-writing, and proofreading - have long been the subject of investigation and are proven to equally contribute to the effectiveness and quality of written production. The aim of this study is to focus on the stage of self-editing in written production and identify the role of self-editing in micro skills development. Teachers need to be aware of their students' needs and, in order to determine these, need to analyze the errors made by their students in written production. Thus, this study also intends to report on typical errors made by learners and examine whether students effectively edit for errors during revision and whether additional editing instruction helps reduce errors in revised essays written in ESL.

\section{Materials and Methods}

\section{Literature Review}

Over the last decade, the research literature has focused much on the written genres, since they provide a wide scope for research, including the most problematic areas in the field and ways of tackling them. A. Levinzon (2014, pp. 29-32) analyzes the reasons for the relatively poor writing skills of Russian schoolchildren and makes some suggestions on how to deal with them. She claims that these could be due to 1) less importance given to speech development in the school curriculum than to grammar, spelling or punctuation, which leads to the underdevelopment of critical writing; 2) inappropriacy of the topics of essays in a number of Russian textbooks provided to students since topics are not aimed at adolescents' emotional experience, discussing controversial issues and expressing the voice of the writer. Y. Ahapkina (2013, pp. 88-90) also touches upon some long-term and contextual reasons for deviations from standard speech in the written language of native speakers who create an academic text: for example, students' extreme inattentiveness to information given for contemplation; their disinterest in acquiring the skill of perceiving flows of information; their surprising indiscriminateness in their own writing and that of their peers. She also depicts the most frequent errors students commit in their essays in the native language, among which are concordance, word formation, the usage of linking words and phrases, and intensifiers.

It is necessary to note that Brown distinguishes between mistakes and errors, which he considers to be technically different phenomena (Brown, 2007, pp. 257-258). Mistakes are intrinsic in both native and second language and are seen as slips or performance errors which can be easily self-corrected, whereas errors manifest the language competence of the learner. Error analysis should be an integral part of the language acquisition process during which learners benefit from various forms of feedback on the errors they commit. Investigations into the nature and effects of error correction were attempted by a number of researchers. Much debate arose when J. Truscott (1996) published his review essay "The Case against Grammar Correction in L2 Writing Classes”, which considers error correction as unnecessary and even harmful. Most researchers, however, agree that learners should be initiated into correction activity in various forms. Notably, D. Ferris and B. Roberts (2001, p. 161) as well as J. Bitchener (2008, p. 102) claim that, despite controversial opinions on the efficacy of error feedback, most studies on error correction in L2 writing classes have provided evidence that students who receive error feedback from teachers improve in accuracy and overall quality over time. This error feedback from teachers could be provided in different forms, such as direct or indirect corrective feedback. The former is considered as "the provision of the correct linguistic form or structure above or near the linguistic error" (Bitchener, 2008, p. 105). Such direct correction can be done in different forms from crossing out the wrong word or phrase and writing the correct one above it or in the margin, to oral meta-linguistic explanations in which the rules and examples are presented, practiced, and discussed. Indirect corrective feedback provides less explicit correction through underlining the error and using a code to indicate what type of error has occurred so that students can improve their piece of writing by themselves (Bitchener, 2008, p. 105; Diab, 2010, p. 91; Ferris et al., 2013, p. 328).

Some research is also devoted to the usefulness of 
peer-review in the writing process. Reichelt (1999, p. $195)$ proves that peer-editing can improve students' language ability by reducing the frequency of their errors. Harris and Brown (2013, p. 110) consider peer-assessment along with self-assessment under the combined term PASA, coming to the conclusion that "although PASA accuracy is important it seems unlikely that students will feel confident in their own evaluations without guidance and support from their teacher" at least at the secondary school level. Diab (2010, p. 92) expresses a similar opinion in favor of peer-assessment, having found that engaging student writers in peer-editing reduced their rule-based language errors in revised drafts more than those who self-edited their essays. R. Santagata (2005, p. 504) also claims that handing over the mistake management activity to students alone does not assure a high-level reasoning process on their part nor does it assure significant elaboration of the mistake. Mistakes tend to be elaborated more when the correction is given by the teacher.

However, it is important to note that self-editing seems to be undervalued. In particular, Ferris and Roberts (2001, p. 166) studied the differences in student editing success ratios across five major categories of error - verbs, noun endings, articles, word choice, and sentence structure. They concluded that less explicit feedback seemed to help students to self-edit just as well as corrections coded by error type. Furthermore, Ferris (2004, p. 58) categorized errors into lexical, morphological, and syntactic categories while Bitchener (2008, p. 102) targeted only articlebased mistakes. In this study, the analysis of different error categories has been implemented in order to identify the most problematic areas in students' academic writing and clarify what role self-editing has to play in developing micro-skills in writing.

\section{Methodology}

The study was conducted to answer the research question: whether self-editing as a final component of written production can boost writing micro skills of learners. It is based on a corpus of essays produced by 50 full-time students, randomly chosen at the beginning and at the end of their second year of study in the Faculty of Economics of the National Research University Higher School of Economics, Moscow. All of them were non-native speakers of English. At the time of data collection, all the participants were taking EAP classes in preparation for a mock exam designed according to the IELTS standard. The compulsory course of EAP is generally taught over two academic years. During the first year, paragraph writing is addressed, while the second year focuses more on comprehensive writing, particularly essays. In addition, the syllabus suggests a simultaneous course of English for specific purposes (ESP). Although most students have passed the Unified State Examination in the English language, their level of English varies. Ideally, their level of English should correspond to the B2 level of the CEFR, which is identical to an IELTS score of 5-6.

The following criteria were applied to the written assignments set for students. The task was set pretty openly in the course syllabi. The students were expected to provide a comprehensive analysis of the problem stated in the topic of their assignment and present a solution to the problem, express their own opinion and provide well-balanced argumentation. The word limit in the written assignments was originally set at a minimum of 250 words in accordance with the IELTS standard, and the total time allocated for the task was 40 minutes. There was no special selection of essays for students with higher or lower levels of English, which generally varied from Pre-Intermediate to Upper Intermediate.

Criteria for the essay assessment were the same as those in IELTS writing band descriptors for Task 2 (public version) and included such components as:

1) task response - Task 2 requires the candidates to formulate and develop a position in relation to a given prompt in the form of a question or statement. Ideas should be supported by evidence, and examples may be drawn from the candidates' own experience;

2) coherence and cohesion - this criterion concerns the overall clarity and fluency of the message: how the response organizes and links information, ideas and language. Coherence refers to the linking of ideas through logical sequencing. Cohesion refers to the varied and appropriate use of cohesive devices (for example, logical connectors, pronouns and conjunctions) to assist in making the conceptual and referential relationships between and within sentences clear;

3) lexical resource - this criterion refers to the range of vocabulary the candidate has used and the accuracy and appropriacy of that use in terms of the specific task;

4) grammatical range and accuracy - this criterion refers to the range and accurate use of the candidate's grammatical resource as manifested in the candidate's writing at the sentence level.

Essay topics being of general interest to the public (about music, education, crime and punishment) were as follows:

- Music is played in every society and culture in the world today. Some people think that music brings only benefits to individuals and society. However, others think that music can have a negative effect on both. Discuss both points of view and express your own opinion. 
- Some people believe that exams are an inappropriate way of measuring students' performance and should be replaced by continuous assessment. To what extent do you agree or disagree with this view?

- Some people argue that universities should provide students with more practical training for their future career. Should university education be more vocational or academic?

- Some people believe that there should be fixed punishments for each type of crime. Others, however, argue that the circumstances of an individual crime, and the motivation for committing it, should always be taken into account when deciding on the punishment. Discuss both these views and give your own opinion.

At the beginning of the second year, after students had been introduced to the basic concepts of essay writing, types of essays and criteria used for assessment, they were asked to write a diagnostic inclass IELTS-type essay in 40 minutes.

At the next stage of the experiment, the essays were analyzed and each occurrence of an error was carefully examined in the wider context in which the error occurred and was then classified according to its specific area. In particular, errors frequently concerned formal aspects (the layout of the paper and its structure) as well as linguistic-stylistic aspects (grammar and spelling, choice of lexis, stylistics, and punctuation). Then the frequency of each type of error in the essays was calculated in percentage terms (See Table 1). During the course, learners were consistently involved in revision of features of academic writing, along with grammatical and lexical aspects, with the focus on error correction exercises. The choice of revised features was based on the most frequent errors made by students. Meanwhile the students were also asked to make a list of the typical errors they tend to commit in their own written assignments and, considering these specific errors, spend 10 minutes on editing each of their consecutive essays written during the course. At the end of the semester, a final diagnostic timed essay was implemented, with errors being analyzed afterwards in percentage terms (see Table 2).

\section{Results and Discussion}

The findings of this study suggest that L2 writing students can improve their own writing by transferring micro skills they learn when editing texts. The results of the essay analysis are in line with those obtained by Ferris et al (2001, p. 172; Ferris, 2004, p. 53; Bitchener, 2008, p. 102). Table 1 shows the types of error committed by learners and their frequency divided according to the criteria used in assessing the written assignments.

As demonstrated in table 1 , students' weakest point concerning the formal aspect of writing seems to be the structure of paragraphs, which usually consists of a thesis statement, some supporting sentences containing ideas and examples, and a concluding sentence. It is often difficult for students to distinguish between the topic sentence and supporting ideas since they fail to generalize ideas. Thus, students do not provide well-balanced argumentation (27\% of essays), which often leads to insufficient length (in $7 \%$ of essays), mainly due to a lack of ideas generated within the time provided for the written task. In addition, the introduction does not clearly state the topic of the essay (in 13\% of cases). The conclusion, which should express the writer's opinion, is often not persuasive enough (9\%).

However, the most frequent basic errors committed by students concern the linguistic-stylistic aspects related to use of articles, prepositions, and concordance between subject and predicate. Undoubtedly, articles are the most problematic elements for Russian students writing in English due to the lack of this grammatical element in their native language. The use of articles with determiners (another/other/ the other, etc) also presents notable difficulties for students, with a significant $82 \%$ of the essays analyzed containing this error. Incorrect use of prepositions was found in just over half of the essays (56\%). The most frequent examples - related with, can influence on, dependent from, invest to, reasons of, rise on 30\%, listen something - again demonstrate the interference of the Russian language when students rely on a wordto-word translation from their native language. On the other hand, other incorrect prepositions reveal errors of a different nature (by radio, by/in the other hand, at morning, despite of, etc) showing some gaps in students' knowledge in this area. Students often use prepositions such as and/but in the initial position while Biber et al. (1999, p. 84) claim that "the prescription against initial coordinators seems most influential in academic prose." Almost half of all essays revealed problems with concordance in subject and predicate. These, however, can be considered as slips due to students' inattentiveness (music improve, method don't, there is songs, people enjoys, etc) and could be easily removed through proofreading. However, other instances of this mistake could be due to insufficient knowledge in the corresponding areas of English grammar (the majority of universities provides, etc). On the whole, both grammatical and spelling mistakes could be eliminated by allowing time to proofread the written work, or using the Spellchecker or peer-review.

In the stylistic category of error type, students usually have difficulties with the following aspects: 
Table 1

Typical errors in students' essays (\%) at the beginning of the course

\begin{tabular}{|c|c|c|c|c|c|c|c|}
\hline \multicolumn{2}{|c|}{ Task Response } & \multicolumn{2}{|c|}{ Cohesion/Coherence } & \multicolumn{2}{|c|}{ Lexical Resource } & \multicolumn{2}{|c|}{$\begin{array}{l}\text { Grammatical Range } \\
\text { and Accuracy }\end{array}$} \\
\hline Type of error & $\begin{array}{l}\text { Occurrence } \\
\text { (\%) }\end{array}$ & Type of error & $\begin{array}{l}\text { Occurrence } \\
\text { (\%) }\end{array}$ & Type of error & $\begin{array}{c}\text { Occurrence } \\
(\%)\end{array}$ & Type of error & $\begin{array}{c}\text { Occurrence } \\
(\%)\end{array}$ \\
\hline wrong layout & 6 & linking words & 5 & wrong word & 44 & articles & 82 \\
\hline $\begin{array}{l}\text { no problem } \\
\text { stated in } \\
\text { introduction }\end{array}$ & 13 & illogical ideas & 11 & $\begin{array}{l}\text { wrong } \\
\text { collocation }\end{array}$ & 46 & $\begin{array}{l}\text { noun/verb } \\
\text { concord }\end{array}$ & 49 \\
\hline $\begin{array}{l}\text { not per- } \\
\text { suasive } \\
\text { conclusion }\end{array}$ & 9 & $\begin{array}{l}\text { no central } \\
\text { idea in } \\
\text { paragraphs }\end{array}$ & 22 & $\begin{array}{l}\text { lexical } \\
\text { register }\end{array}$ & 3 & prepositions & 56 \\
\hline register & 14 & $\begin{array}{l}\text { weakly } \\
\text { developed } \\
\text { argumenta- } \\
\text { tion }\end{array}$ & 27 & spelling & 44 & word order & 5 \\
\hline $\begin{array}{l}\text { irrelevant } \\
\text { information }\end{array}$ & 3 & repetition & 8 & word form & 12 & passive voice & 15 \\
\hline \multirow[t]{2}{*}{ underlength } & 7 & & & & & $\begin{array}{l}\text { countable/ } \\
\text { uncountable } \\
\text { nouns }\end{array}$ & 16 \\
\hline & & & & & & punctuation & 21 \\
\hline
\end{tabular}

Table 2

Typical errors in students' essays (\%) at the end of the course

\begin{tabular}{|c|c|c|c|c|c|c|c|}
\hline \multicolumn{2}{|c|}{ Task Response } & \multicolumn{2}{|c|}{ Cohesion/Coherence } & \multicolumn{2}{|c|}{ Lexical Resource } & \multicolumn{2}{|c|}{$\begin{array}{l}\text { Grammatical Range } \\
\text { and Accuracy }\end{array}$} \\
\hline Type of error & $\begin{array}{l}\text { Occurrence } \\
(\%)\end{array}$ & Type of error & $\begin{array}{c}\text { Occurrence } \\
(\%)\end{array}$ & Type of error & $\begin{array}{c}\text { Occurrence } \\
(\%)\end{array}$ & Type of error & $\begin{array}{c}\text { Occurrence } \\
(\%)\end{array}$ \\
\hline wrong layout & 3 & linking words & 4 & wrong word & 31 & articles & 53 \\
\hline $\begin{array}{l}\text { no problem } \\
\text { stated in } \\
\text { introduction }\end{array}$ & 4 & illogical ideas & 10 & $\begin{array}{l}\text { wrong } \\
\text { collocation }\end{array}$ & 32 & $\begin{array}{l}\text { noun/verb } \\
\text { concord }\end{array}$ & 29 \\
\hline $\begin{array}{l}\text { not per- } \\
\text { suasive } \\
\text { conclusion }\end{array}$ & 5 & $\begin{array}{l}\text { no central } \\
\text { idea in } \\
\text { paragraphs }\end{array}$ & 18 & $\begin{array}{l}\text { lexical } \\
\text { register }\end{array}$ & 2 & prepositions & 41 \\
\hline register & 9 & $\begin{array}{l}\text { weakly } \\
\text { developed } \\
\text { argumenta- } \\
\text { tion }\end{array}$ & 25 & spelling & 28 & word order & 4 \\
\hline $\begin{array}{l}\text { irrelevant } \\
\text { information }\end{array}$ & 3 & repetition & 6 & word form & 9 & passive voice & 10 \\
\hline \multirow[t]{2}{*}{ underlength } & 5 & & & & & $\begin{array}{l}\text { countable/ } \\
\text { uncountable } \\
\text { nouns }\end{array}$ & 5 \\
\hline & & & & & & punctuation & 11 \\
\hline
\end{tabular}


register and appropriacy (14\%) and incorrect choice of a word or a phrase (46\%). Concerning register and appropriacy, students are often unaware of using certain words in an inappropriate register in academic language, including abbreviations. Incorrect choice of a word or a phrase (wrong collocations) can be due to polysemy in English when students find it especially difficult to choose the correct meaning of a word according to the particular context. Examples of such misuse are as follows: make the job, do crimes, make crime, make homework, do order, do mistakes, make research; increase mood, heal people's emotions, broadcast culture, measure education/ performance/students, perform knowledge, hard crimes, attend sport, visit university; found business, bring up program, economical crisis, low-quantity job, development countries. This aspect is also closely related to the interference of the native language. Students oftentimes use the words which exist in English but with a different meaning, so-called 'false friends'; for example, expertise, complexion, etc. Among mechanical errors, the most common concern punctuation, namely, the use of commas after a subordinate sentence, which precedes the main clause, or after fronting a word or a group of words to add something to the main part of the sentence, usually adverbials: however, for instance, for example, finally, in my opinion. On the other hand, commas are wrongly used before the pronoun that, or in a defining relative clause, which in English is considered a very serious mistake. By contrast, in the Russian language, such use of a comma is a must; for example, "I think/believe/ know, that... Nowadays the science is highly developed in different spheres, especially in those, which are connected with education."

Another common mistake is a lack of tentativeness - hedging - in students' written works in which they express themselves very straightforwardly; for example, This is a ridiculous idea. On this issue, Biber et al. (1999, p. 980) state that "it is not at all uncommon to find personal attitudes and estimates of likelihood expressed in academic writing through impersonal stance devices such as modal verbs, adverbials, and extra posed complement clauses".

Table 2, which depicts the results of the essay analysis implemented at the end of the course with types of error categorized according to the same criteria, illustrates that the outcome proved to be better than in the first diagnostic test. In terms of task response, learners improved the quality of their essays by approximately $50 \%$ in terms of layout, particularly in the introduction and conclusion, and also in terms of register, with no changes in the relevancy of information applied. Cohesion and coherence, however, proved to be much more challenging aspects to acquire, with only a very slight improvement of 1-4 errors per category. Lexical resource and grammatical range and accuracy, areas in which the vast majority of errors are committed, improved by nearly $30 \%$.

Based on a statistical analysis of learners' errors made separately according to assessment criteria, Appendix A provides evidence that, in $95 \%$ of all cases, there has been a significant shift in the level of knowledge, with students showing more proficiency at the end of the course than at the beginning. After sufficient instruction provided by the teacher and through self-editing, the students were able to significantly improve their skills in dealing with the formal aspects of the essays (the layout of the paper and its structure) as well as some types of error related to linguistic-stylistic aspects (grammatical accuracy and spelling, stylistics, and punctuation). Cohesion and coherence, however, improved only slightly, which prompts the conclusion that these are the most challenging areas for students.

\section{Conclusion}

Results from this study indicate that those students who are involved in self-correction during written production improved in specific areas of writing. After this study sought to explore some of the most typical errors that non-native students of English make in writing essays, it examined the influence of selfediting on improving students' micro skills in writing. The results show that by the end of the semester, the quality of the written assignments had significantly improved compared to the beginning of the academic year. The micro skills of learners, such as linguistic accuracy in correct use of grammatical structures, appropriate word forms and collocations, spelling and punctuation, had to some extent improved after selfediting instruction and feedback. It is essential to note that the degree of improvement depends largely on the amount of time provided for editing. After instruction sessions, when students were allowed more time to self-edit essays, the occurrence of mistakes decreased noticeably. However, since students are limited by time and often do not have sufficient time for editing while writing essays, the results are not so impressive. This refers mainly to rule-based errors, which can be rather easily erased after appropriate instruction and sufficient practice. The same cannot be said for non rule-based errors, such as word collocations, correct choice of words, coherence or developing argumentation, which demand more time and practice and might be erased over time. Thus, different types of errors are likely to require varying treatments (Ferris, 2004, p. 60).

That is why a more practical approach to developing micro skills in academic writing and more focus are necessary. This study can help teachers to 
reflect on their students' writing and guide how they instruct students on the above-mentioned challenges in order to improve students' formal written speech and, consequently, their oral competence. There is a need for teachers to train themselves in competent error correction; they must plan for this carefully in designing their courses, and they must execute it faithfully and consistently by assisting learners in vocabulary learning and expanding the list of grammatical constructions that are taught through analysis of written texts. Only by developing understanding of the difficulties encountered by students and the underlying reasons for these can teachers help students gain control over their writing and meet the challenges of academic writing during the process of second language acquisition. "L2 student writers want, expect, and value teacher feedback on their written errors" in different forms (Ferris et al., 2001, p. 166).

To this end, teachers need to focus on those parts of language that are significant in the writing process and present some difficulties for students. Errors provide certain feedback for teachers because they reflect the effectiveness of teaching materials and teaching techniques, revealing what parts of the syllabus have been inadequately learned or taught and require further attention (Keshavarz, 1992, pp. 23-24). The challenge for teachers is to extrapolate from earlier student essays and apply these findings in a personalized instructional design for each student. This can be used as a basis for planning revising lessons and exercises.

As Brown (2007, p. 259) states, errors arise from different sources: "interlingual errors of interference from the native language; intralingual errors within the target language; the sociolinguistic context of communication; psycholinguistic or cognitive strategies, and numerous affective variables." Bearing this in mind, it is essential for teachers to make sure that students have access to additional courses such as Academic Writing, Critical Thinking, including online courses, etc. Students need to be encouraged to find ways of using the language that they feel are expressive of their own needs and desires, to read more, to write, speak and listen in the foreign language making efforts to think critically about what was perceived and produced. Students should be taught how to monitor their written output and slowly convert systematic errors into appropriate forms. It is through error analysis that learners can come to improving their micro skills in writing such as producing appropriate sentence structures with acceptable choice of words, grammatical systems, spelling, punctuation, and using cohesive devices, at an efficient rate of speed. After becoming aware of both common errors and their own typical errors, learners can engage in improving these particular weak fields; after a while, they will not hesitate about the appropriacy of their output and will automatically make the necessary differentiation between the correct and incorrect application of existing rules. Error analysis is thus a way for students to become more independent, self-regulated learners: "Self-regulated learning refers to the processes by which students attempt to monitor and control their own learning" (Baranovskaya, 2015, p. 38). Specifically, active engagement in self-editing may contribute to learners' motivation and confidence. It also seems reasonable to agree with Santagata who claims that "students may need some consciousness-raising ... about why linguistic accuracy and editing skills are important. ... And they need practice, accountability, and the opportunity to engage cognitively in editing as a problem-solving process" (Santagata, 2005, p. 59). Thus, the challenging task for teachers is to facilitate students in developing viable strategies for getting started, drafting, re-writing and editing in order to produce good, error-free written output.

\section{References}

Ahapkina, Y. E. (2013). Prichinyi i mehanizmyi rechevyih sboyev na pis'me [The causes and mechanisms of speech disruptions in writing]. Educational Studies, 3, 65-91.

Baranovskaya, T. A. (2015). Self-regulation skills: Several ways of helping students develop selfregulated learning. Journal of Language \& Education, 1(1), 37-45.

Baranovskaya, T. A., Vasiliyeva, I. B., Shaforostova, V. M. (2011). Razvitie navykov akademicheskogo pis'ma. Podgotovka studentov $k$ gosudarstvennomu jekzamenu po anglijskomu jazyku v NIU VShJe: Lingvisticheskaja chast' (opisanie grafika) [The development of academic writing skills. Preparing students for the state exam in English in the HSE: Linguistic part (graph description)]. Modern Humanities Research, 5, 52-56.

Biber, D., Johansson, S., Leech, G., Conrad, S., \& Finegan, E. (1999). Longman grammar of spoken and written English. Harlow, UK: Longman.

Bitchener, J. (2008). Evidence in support of written corrective feedback. Journal of Second Language Writing, 17, 102-118.

Brown, H.D. (2004). Language assessment and classroom practices. New York, NY: Pearson Education Limited.

Brown, H. D. (2007). Principles of language learning and teaching (5th ed.). New York, NY: Pearson Education Limited.

Council of Europe. (2011). Common European framework of reference for languages: Learning, teaching, assessment. The development of academic 
writing skills. Preparing students for the state exam in English in the HSE: Linguistic part (graph description) (12th ed.). Cambridge, UK: Cambridge University Press.

Diab, N. M. (2010). Effects of peer- versus self-editing on students' revision of language errors in revised drafts. System, 38, 85-95.

Ferris, D. R. (2004). The "Grammar correction" debate in L2 writing: Where are we, and where do we go from here? (and what do we do in the meantime. . .?). Journal of Second Language Writing, 13, 49-62.

Ferris, D. R., Liu, H., Sinha, A., \& Senna, M. (2013). Written corrective feedback for individual L2 writers. Journal of Second Language Writing, 22, 307-329.

Ferris, D., Roberts, B. (2001). Error feedback in L2 writing classes: How explicit does it need to be? Journal of Second Language Writing, 10, 161-184.

Gillett, A. J. (1996). What is EAP? IATEFL ESP SIG Newsletter, 6, 17-23. Retrieved from http://www. uefa com/articles/ea htm

Harris, L. R., Brown Gavin, T. L. (2013). Opportunities and obstacles to consider when using peer- and self-assessment to improve student learning: Case studies into teachers' implementation. Teaching and Teacher Education, 36, 101-111.

IELTS Writing band descriptors: Task 2. (2016). Retrieved from http://www.ielts.org>PDF/UOBDs_ WritingT2.pdf
Keshavarz, M. H. (1992). Contrastive analysis and error analysis: From theory to practice. Tehran, Iran: Rahnama Publication.

Kobzar, A. I. (2006). Prikladnaja matematicheskaja statistika [Applied mathematical statistics]. Moscow, Russia: Fizmatlit.

Levinzon, A. I. (2014). Kreativnoe pis'mo: Model' anglojazychnyh stran $\mathrm{v}$ rossijskoj shkole [Creative writing: A model of English-speaking countries in the Russian school]. Educational Studies, 1, 25-45.

Reichelt, M. (1999). Toward a more comprehensive view of L2 writing: Foreign language writing in the US. Journal of Second Language Writing, 8(2), 181204.

Santagata, R. (2005). Practices and beliefs in mistakehandling activities: A video study of Italian and US mathematics lessons. Teaching and Teacher Education, 21, 491-508.

TEAL Center. (2010). Research-based writing instruction. TEAL center fact sheet, 1, 1-3. Retrieved from https://teal.ed.gov/resources

Truscott, J. (1996). The case against grammar correction in L2 writing classes. Language Learning, 46, 327-369.

Wilcoxon, F., Rhodes, L. J., \& Bradley, R. A. (1963). Two sequential two-sample grouped rank tests with applications to screening experiments. Biometrics, $19,58-84$. 


\section{Appendix A}

Since observations are rather limited, having been undertaken only at the beginning and at the end of the course, it cannot be said that they are made from exponential population with known probability distribution. In this case it was appropriate to apply the analysis of non-parametric criteria, such as a rankbased Wilcoxon test. In this test data are constructed as follows. For two samples $\mathrm{x} 1$ and $\mathrm{x} 2$ of the same size $\mathrm{n}$, the number of differences $\mathrm{x} 2-\mathrm{x} 1$ is calculated, which is then ranked in the ascending order. In the ordered series of values of $\mathrm{x} 2-\mathrm{x} 1$ the sum of ranks (T) of positive differences can be seen (Kobzar, 2006). A "typical" shift is significantly predominant in intensity, if T emp is below or equal to T' 0.05 , and even more significantly predominant if $\mathrm{T}$ emp is less than or equal to T' 0.01 . In our case $\mathrm{x} 1$ corresponds to typical errors in students' essays (\%) at the beginning of the course, x2 means typical errors in students' essays (\%) at the end of the course.

Table 3 shows the critical value of the $\mathrm{T}$ criterion by Wilcoxon et al. for the levels of statistical significance $\rho \leqslant 0.05$ and $\rho \leqslant 0.01$ (Wilcoxon et al., 1963).

In Table 2, T equals 0 (the sum of ranks of positive differences), which is below the critical value of T'0.05=2.

In Table 3, $\mathrm{T}=0$ (the sum of ranks of positive differences), which is equal to the critical value of T' $0.05=0$.

In Table $4, \mathrm{~T}=0$ (the sum of ranks of positive differences), which is equal to the critical value of T' $0.05=0$.

In Table $5, \mathrm{~T}=0$ (the sum of ranks of positive differences), which is below the critical value of T' $0.05=3$.

Table 1

Levels of statistical significance $(\rho)$

\begin{tabular}{ccc}
\hline $\mathrm{n}$ & \multicolumn{2}{c}{ Levels of statistical significance $(\rho)$} \\
& 0.05 & 0.01 \\
\hline 5 & 0 & - \\
6 & 2 & - \\
7 & 3 & 0 \\
\hline
\end{tabular}

Table 2

Task response

\begin{tabular}{lccc}
\hline \multicolumn{1}{c}{ Type of error } & $\mathbf{x} \mathbf{1}$ & $\mathbf{x} \mathbf{2}$ & $\mathbf{x 2}-\mathbf{x} \mathbf{1}$ \\
\hline wrong layout & 6 & 3 & -3 \\
no problem stated in introduction & 13 & 4 & -9 \\
not persuasive conclusion & 9 & 5 & -4 \\
register & 14 & 9 & -5 \\
irrelevant information & 3 & 3 & 0 \\
under length & 7 & 5 & -2 \\
\hline
\end{tabular}

Table 3

Cohesion/coherence

\begin{tabular}{lccc}
\hline \multicolumn{1}{c}{ Type of error } & x1 & x2 & x2-x1 \\
\hline wrong layout & 6 & 3 & -3 \\
linking words & 5 & 4 & -1 \\
illogical ideas & 11 & 10 & -1 \\
no central idea in paragraphs & 22 & 18 & -4 \\
weakly developed argumentation & 27 & 25 & -2 \\
repetition & 8 & 6 & -2 \\
\hline
\end{tabular}

Table 4

Lexical resource

\begin{tabular}{lccc}
\hline \multicolumn{1}{c}{ Type of error } & x1 & x2 & x2-x1 \\
\hline wrong word & 44 & 31 & -13 \\
wrong collocation & 46 & 32 & -14 \\
lexical register & 3 & 2 & -1 \\
spelling & 44 & 28 & -16 \\
word form & 12 & 9 & -3 \\
\hline
\end{tabular}

Table 5

Grammatical range and accuracy

\begin{tabular}{lccc}
\hline \multicolumn{1}{c}{ Type of error } & x1 & x2 & x2-x1 \\
\hline articles & 82 & 53 & -29 \\
noun/verb concord & 49 & 29 & -20 \\
prepositions & 56 & 41 & -15 \\
word order & 5 & 4 & -1 \\
passive voice & 15 & 10 & -5 \\
countable/uncountable nouns & 16 & 5 & -11 \\
punctuation & 21 & 11 & -10 \\
\hline
\end{tabular}

